\title{
Archaeometry and cultural heritage: contributions of geosciences
}

\author{
Lara Maritan $^{1} \cdot$ Germana Barone $^{2} \cdot$ Marco Benvenuti $^{3}$
}

Received: 18 October 2015/ Accepted: 18 October 2015/Published online: 6 November 2015

(C) Accademia Nazionale dei Lincei 2015

\begin{abstract}
"This volume Archaeometry and Cultural Heritage: contributions of Geosciences is dedicated to Claudio D'Amico, Professor Emeritus of the University of Bologna (Italy), former professor in petrography, who devoted part of his academic research activity to the application of petrography to the study of cultural heritage. $\mathrm{He}$ is a reference figure, since he has devoted his career to integrating Italian geoscientists in the scenario of archaeometry".
\end{abstract}

This Special Issue of the Rendiconti Lincei Scienze Fisiche e Naturali includes a selection of the papers presented at the Session S11 "Archaeometry and Cultural Heritage: the contribution of Geosciences" during the conference "The future of the Italian Geosciences, the Italian Geosciences of the future" (Milano, Italy, September 10-12, 2014), coorganised by the Società Geologica Italiana and Società Italiana di Mineralogia e Petrologia. A total of forty-four papers were presented, eighteen as oral communications

Lara Maritan

lara.maritan@unipd.it

Germana Barone

gbarone@unict.it

Marco Benvenuti

m.benvenuti@unifi.it

1 Dipartimento di Geoscienze, Università di Padova, Via Gradenigo 6, 35131 Padua, Italy

2 Dipartimento di Scienze Biologiche, Geologiche e Ambientali, Università di Catania, Corso Italia 57, 95129 Catania, Italy

3 Dipartimento di Scienze della Terra, Università di Firenze, Via La Pira 4, 50121 Florence, Italy and twenty-six as posters. Session S11 saw great participation on the part of researchers from almost all Italian Earth Sciences Departments working in the Cultural Heritage field, and represented an important occasion on which to review the state-of-the-art of methodological developments and characterisation studies of ancient materials in Italy. The participation of both experienced, well-known specialists and young scientists (recent graduates and $\mathrm{PhD}$ students) was an important opportunity in which to develop new ideas, set up new collaborations and organise networks, especially among our younger colleagues.

The papers presented in this Special Issue cover a wide range of topics, from provenance and production technology to methodological developments, and deal with many types of materials, from stone to pottery, mortars, plasters, and glass. In particular, the first articles of this Special Issue feature provenance studies of rocks, both in terms of analysis of ancient artefacts and of definition of reference datasets of rocks from ancient quarries. They were followed by papers devoted to mortar-based materials and the production technology of mural painting. The last part of the volume comprises archaeometric studies of pottery and vitreous ornaments, obtained from the pyrotechnological transformation of raw materials, and the development of a miniaturised instrument for the analysis of cultural heritage materials.

The first paper of the Special Issue contains the opening lecture by Alessandro Borghi and co-authors, who presented the results of an extensive petrographic study on the statuary of the Egyptian Museum of Turin, focusing on the definition of the area from which the rock used was exploited. This was also an opportunity to reinterpret the origin of the "Bekhen Stone". 
Antonelli and Lazzini presented new petrographic and isotopic data to integrate the existing databases for the main Mediterranean white marble quarries exploited in Greek and Roman times. The combined measures of the maximum grain size and of carbon and oxygen stable isotope ratios represent the most effective method to determine the provenance of the white marbles used in antiquity.

The petrographic and geochemical characterisation of the Portoro black marble by Fratini and co-authors was associated here with a very interesting study on the causes of colour changes of a special variety of the rock (macchia marga) when exposed to weathering, which makes this variety not suitable for outdoor use.

The geological exploration and mapping of the Quaternary succession of the Bulè and the low Alpetto tributary valleys (Monviso Massif, Piedmont) allowed Forno and coauthors to identify the occurrence of jadeitite boulderswidely used to produce axe heads in the Neolithic — and to present new ideas about the still controversial origin of these rock types.

The petrographic study of a number of Copper Age stone tools found in the sub-Apenninic area of central Italy allowed D'Amico and co-authors to constrain the provenance of the raw material used for the ophiolitic and sedimentary rocks outcropping in the nearby Apennines, with only a few cases of importation from elsewhere (Tuscany, Marche, southern Italy and South Tyrol).

A first problem dealing with mortar-based materials (mortars and plasters) was that provided by Columbu and co-authors, who used a multidisciplinary approach (including petrographic, petrophysical and mineralogical analyses and digital surveys) to characterise the construction of a Roman bath complex (the Baths of the Emperor Hadrian at Tivoli, Italy).

A second interesting paper was devoted to the mineralogical and petrographic analysis of coloured wall plasters from an ancient hypogeum (fourth-third century BC) in Licata (Sicily, Italy): Raneri and co-authors identified evolving trends in painting technique and the selection of raw materials and pigments for this geographic area.

The petrographic and geochemical study of the pottery production from a Bronze Age settlement near Catania
(Sicily) allowed Rodríguez and co-authors to identify both the source areas of the raw materials and the ceramic production technology. The archaeometric results highlighted the considerable technical skills reached by Bronze Age potters.

Also very interesting was the experimental study by Privitera and co-authors of the morphological and mineralogical changes of microfossils during ceramic firing, which proved useful as a check to reconstruct the firing temperatures of ancient pottery.

The paper of Olmeda and co-authors was devoted to the study of vitreous ornaments in the Roman period: thanks to a multivariate approach (mineralogical and chemical analyses) the authors defined the production technology and established the types of fluxes and colouring agents. They also took the opportunity to discuss the relationship between the studied ornaments and coeval vitreous materials from other regions in the European-Mediterranean area, and to constrain, according to the compositional features, some of the samples to a more restricted production time interval.

The last paper of the issue, by Marinangeli and co-authors, illustrates the potential of an ultra-miniaturised instrument which combines X-ray diffraction and fluorescence, previously used in the exploration of soils/rocks on Mars, to perform non-destructive analysis of ancient artefacts such as pottery and paintings.

Interdisciplinarity and the "multi-analytical approach" characterise the contributions of this Special Issue, showing that researchers with a strong geological background, although in different scientific areas of Geosciences, can answer important questions about ancient materials in terms of provenance, technology and conservation. The papers contained here represent topics and some case studies which, beyond archaeological and historical questions, express the importance of the geological approach in the study of Cultural Heritage materials, from macro- to micro-scale.

Acknowledgments We would like to thank Prof. Francesco P. Sassi, Editor-in-Chief of this journal, for his valuable and essential advice and the devoted assistance during the publication of this Special Issue. 